\title{
openheart How much does a heart valve implantation cost and what are the health care costs afterwards?
}

\author{
Simone A Huygens, ${ }^{1,2}$ Lucas M A Goossens, ${ }^{2,3}$ Judith A van Erkelens, ${ }^{4}$ \\ Johanna J M Takkenberg, ${ }^{1}$ Maureen P M H Rutten-van Mölken ${ }^{2,3}$
}

\begin{abstract}
- Additional material is published online only. To view please visit the journal online (http://dx.doi.org/10.1136/ openhrt-2017-000672).
\end{abstract}

To cite: Huygens SA, Goossens LMA, van Erkelens JA, et al. How much does a heart valve implantation cost and what are the health care costs afterwards?. Open Heart 2018;5:e000672. doi:10.1136/ openhrt-2017-000672

Received 7 June 2017 Revised 21 December 2017 Accepted 29 December 2017

Check for updates

'Department of Cardiothoracic Surgery, Erasmus University Medical Center, Rotterdam, The Netherlands

${ }^{2}$ Department of Health Policy and Management, Erasmus University, Rotterdam, The Netherlands

${ }^{3}$ Institute for Medical Technology Assessment, Erasmus University, Rotterdam, The Netherlands ${ }^{4}$ Vektis, Zeist, The Netherlands

Correspondence to

Simone A Huygens; s.huygens@ erasmusmc.nl

\begin{abstract}
Objective In the era of limited healthcare budgets, healthcare costs of heart valve implantations need to be considered to inform cost-effectiveness analyses. We aimed to provide age group-specific costs estimates of heart valve implantations, related complications and other healthcare utilisation following the intervention.

Methods We performed retrospective analyses of healthcare costs of patients who had undergone heart valve implantations in 2010-2013 and controls using claims data from Dutch health insurers. Heart valve implantations included surgical valve replacement and transcatheter valve implantation in all heart valve positions. Patients were divided in four age groups. Control groups were created by taking random samples of the Dutch population stratified by age, gender, socioeconomic status and comorbidities. We applied non-parametric bootstrapping to address uncertainty of the cost estimates. The association of patient and intervention characteristics with costs was determined by (multilevel) generalised linear models.
\end{abstract}

Results The baseline characteristics of 18903 patients and 188925 controls were comparable. The annual healthcare costs were substantially higher for surgical heart valve replacement patients than for controls, especially in the year of heart valve implantation. Factors associated with increased annual healthcare costs for patients were older age, female gender, comorbidities, low socioeconomic status and complications.

Conclusions We provided a comprehensive overview of age group-specific incidence of heart valve implantations, subsequent survival and complications as well as associated healthcare costs of all patients in the Netherlands. Our results provide real-world costs estimates that can be used as a benchmark for costs of future innovative heart valve implantations.

\section{INTRODUCTION}

Heart valve disease has a profound impact on the use and costs of healthcare. This impact is even greater for heart valve disease than for coronary heart disease, despite the higher prevalence of coronary heart disease. ${ }^{1}$ In developed countries, the prevalence of heart valve disease is $2.5 \%$, and this prevalence is the highest in patients aged $\geq 75$ years $(13.3 \%) .{ }^{2}$ Due to an ageing population,

\section{Key questions}

What is already known about this subject?

Due to the ageing of the population, the number of patients with heart valve disease is expected to increase as is the number of heart valve replacements. The scarcity of resources for healthcare requires an analysis of the impact of this development on costs and cost-effective ness.

- Comprehensive and comparable cost estimates for the entire target population and its subgroups are lacking. The costs of surgical valve replacement and transcatheter valve implantation and subsequent healthcare use have only been estimated for specific risk groups such as elderly high or intermediate surgical risk patients. Moreover, these estimates include only short-term costs.

What does this study add?

- This study adds valuable real-world, age groupspecific cost estimates of all costs associated with heart valve implantations (in all valve positions), including the costs of heart valve implantations itself, complications and healthcare use in the years following the heart valve implantation. Furthermore, this study provides a unique insight in the differences in incidence, health outcomes and (predictors of the) associated healthcare costs of heart valve implantations between patients with different ages.

How might this impact on clinical practice?

- Cost-effectiveness is increasingly becoming an important hurdle for introduction of new interventions in clinical practice. Our results can be used as a benchmark for the costs of new technologies in the field of heart valve implantations that will be introduced in clinical practice in the future, such as tissue-engineered heart valves. To estimate the cost-effectiveness, healthcare decision makers need information about the cost-effectiveness in the real world. Our results provide valuable input for the costs in costeffectiveness analyses of heart valve implantations based on data generated in routine care instead of under experimental conditions. 
the number of patients with heart valve disease requiring valve replacement is expected to rise, reaching more than 800000 annual procedures worldwide by $2050 .{ }^{3}$ As a result, healthcare expenditures and societal burden of heart valve disease will increase.

In patients with severe heart valve disease, replacement of the native valve with a heart valve substitute may be required. There are different effective options, but every heart valve substitute type also has its limitations. ${ }^{4}$ In the future, these limitations may be reduced with the many emerging technologies in the field of heart valve interventions, such as tissue-engineered heart valves and less invasive implantation methods. Before these new technologies can be introduced in clinical practice, it is important to establish that they are effective and cost-effective, considering the scarcity of resources for healthcare. To determine whether a new intervention is cost-effective, the costs and effects of the new intervention need to be compared with current care. Since the choice of heart valve implantation and its outcomes differs substantially among age groups, ${ }^{5}$ it is likely that healthcare costs will also be influenced by patients' age. Hence, having robust age group-specific estimates of the costs of current care is important.

The objective of this study was to estimate the costs of currently used heart valve implantations and also costs of complications as well as healthcare use outside hospitals in the years after heart valve implantations in different age groups. We estimated these costs by retrospective analyses of health insurance claims of patients who had undergone heart valve implantations. This provides valuable real-world age group-specific cost estimates of all costs associated with heart valve implantations, in comparison with previous studies that focused on costs of the heart valve implantation and short-term follow-up in specific age groups only. ${ }^{67}$

\section{METHODS}

\section{Patients}

We used health insurance claims databases ('Vektis') that contain the healthcare expenditures of all the insured in the Netherlands, which is $99 \%$ of all Dutch residents $( \pm 17$ million people). Patients were selected using Diagnosis Related Group (DRG) codes of heart valve implantations (online supplementary table S1). We could distinguish DRG codes for isolated or multiple surgical heart valve replacement (SVR) and transcatheter heart valve implantation (TVI) in every heart valve position with or without concomitant procedures. In the pulmonary and tricuspid valve position, DRG codes did not distinguish between valve repair and replacement; therefore, patients who have undergone repairs in these valve positions are also included in our patient population.

We used data from Vektis for the years 2010-2013. Data before 2010 are generally considered less valid. On the date of data extraction for this study (January 2016), data from the years 2014 and further were incomplete due to time lags in administrations. Before 2013, there was no specific DRG code for TVI; therefore, we could only include TVI patients in the year 2013.

\section{Controls}

To calculate the excess healthcare costs due to the heart valve implantation, we compared annual healthcare costs of the patient group with a control group. The control group was created by stratified sampling from the remainder of the Dutch insured population in the Vektis databases to ensure that the distributions of person characteristics across the strata were similar to that in the patient population. The control group was 10 times as large as the patient population. Strata were based on age class, gender, socioeconomic status (SES) and comorbidities. Age was divided into nine age classes: $0-1,2-18$, 19-30, 31-40, 41-50, 51-60, 61-70, 71-80 and >80 years. SES was based on status scores reflecting the SES of a district based on characteristics of its residents: education, income and position on the labour market. ${ }^{8}$ The status scores were divided in four groups based on percentiles, with lower percentiles representing lower SES. Comorbidities were based on Pharmacy Cost Groups, which is an outpatient morbidity measure based on prior use of prescribed drugs as marker for chronic conditions. ${ }^{9}$ The strata used for comorbidities differed per age class because of differences in prevalence of comorbidities (see online supplement).

\section{Healthcare costs}

Patients were followed over time from the opening date of the heart valve implantation DRG in the financial administrative system until death or until 31 December 2013, whichever occurred first, to assess whether they experienced complications after the heart valve implantation and to collect their other healthcare costs besides the costs of heart valve implantation itself.

For every patient, the costs of the initial heart valve implantation and the healthcare costs during the first postintervention year and subsequent (max. 4) years were determined. Costs were defined as expenditures reimbursed by health insurers and expressed in euros $(€)$. The procedure costs included the costs of the DRG and intensive care unit (ICU) stay. We assumed that the costs of ICU stay in the first postintervention year excluding the ICU costs related to specific complications were related to the heart valve implantation.

Complications were extracted from the Vektis database using DRG codes for treatment of complications (online supplementary table S2). The complications of interest were based on the conceptual model we have developed previously. ${ }^{5}$ The following complications were available in the Vektis database: acute kidney injury, atrial fibrillation (AF), stroke, transient ischaemic attack, prosthetic valve endocarditis (conservative treatment), myocardial infarction, pacemaker implantation and reintervention (redo heart valve implantation). For every complication, costs (DRG+ICU costs), proportions of 
patients admitted to the ICU and number of ICU days were determined.

For both patients and controls, annual healthcare costs were determined. The starting point of the calculation of annual healthcare costs of patients is the quarter in which the heart valve implantation was performed. The annual healthcare costs were classified into costs of general practitioners, specialised medical care (both inpatient and outpatient care, including costs of DRGs, ICU stay, medicines on the expensive drugs list, primary care diagnostics and other costs), pharmaceuticals, paramedical care, patient transport, home care, nursing homes and geriatric rehabilitation care. Cost of medicines on the expensive drug list, home care, nursing homes and geriatric rehabilitation care were only available in the Vektis database from the year 2012 onwards.

\section{Statistical analysis}

The statistical analyses were performed with SAS V.9.4 using SAS Enterprise Guide V.7.1.

\section{Descriptive analyses}

Patients and controls were divided in four age groups: children (0-18 years), young adults (19-60 years), middle aged (61-70 years) and elderly patients ( $>70$ years). For every age group, we performed descriptive analyses of person and intervention characteristics, occurrence of complications and healthcare costs. Continuous variables were depicted as means and standard deviation (SD) or 95\% confidence interval (CI) and discrete variables as counts and proportions. We assessed survival after SVR and TVI using KaplanMeier estimates. The difference between mean healthcare costs of patients and controls was calculated; mean costs of controls were based on the same calendar years as patients (eg, for patients postintervention year 2 could be between 2011 and 2013; therefore, these costs were compared with the average costs of controls in 2011-2013). As the cost data were skewed, non-parametric bootstrapping (2000 replications) was used to address uncertainty (with 95\% CI based on 2.5th and 97.5th percentile) in the annual healthcare costs. To be able to report annual healthcare costs, only patients who were followed the entire year of interest (including patients who died during this year) were included in these analyses.

\section{Association analyses}

To estimate the association between healthcare costs and patient and intervention characteristics, we developed (multilevel) generalised linear models ((M)GLM) for intervention, complication and annual healthcare costs. For annual healthcare costs of patients after heart valve implantations, we estimated a MGLM for children and for adults with normal distributions and identity links and with several observation periods per patient. All patients with at least 1-year complete follow-up were included. We excluded patients with incomplete follow-up in the first post intervention year (except for patients who died) to avoid overestimation of costs per day in post intervention year one due to the high costs in the period after the intervention. To correct for differences in total duration of follow-up, the total healthcare costs were divided by the follow-up duration to estimate average costs per day during the specific year. The independent variables included in the MGLMs for children and adults were time (ie, intervention period (no defined length; includes costs of heart valve implantation and ICU stay), remaining postintervention year 1 and postintervention years 2, 3 and 4), gender and SES. In addition, the model of adults included age groups, comorbidities, mortality and complications. Mortality and the occurrence of complications were time dependent. Comorbidities, mortality and the occurrence of complications were not included in the model for children because there were no children with comorbidities and only a small proportion of children who experienced complications (including mortality). Details about the GLMs in which the costs of interventions and complications were analysed separately can be found in the online supplementary material.

\section{RESULTS}

\section{Study population}

In total, we included 18903 patients (SVR: $\mathrm{n}=17991$, TVI: $\mathrm{n}=912$ ) and 188925 controls. The baseline characteristics of patients and controls were comparable (table 1 ). The mean (median) follow-up was 1.9 (1.9) and $0.4(0.4)$ years for SVR and TVI patients, respectively. Figure 1 illustrates the Kaplan-Meier survival curves after SVR and TVI. During follow-up, 41 children (10.0\%), 841 young adults (26.2\%), 1424 middle-aged patients (29.5\%) and 3036 elderly patients $(31.9 \%)$ experienced one or more complications after SVR. After TVI, six young adults $(18.2 \%)$, two middle aged $(2.9 \%)$ and 157 elderly patients $(19.4 \%)$ experienced complications.

Table 2 presents the occurrence of complications per postintervention year, the proportion of patients with ICU stay and the mean length of ICU stay after complications.

\section{Healthcare costs: descriptive analyses}

Table 3 and figure 2 summarise the costs of heart valve implantations, complications and total annual healthcare costs during the first three postintervention years divided by age group. These costs could not be determined for TVI patients because their follow-up was less than 1 year. The annual healthcare costs of patients were substantially higher than the costs of controls in all age groups, especially in the year of implantation (figure 2; children $€ 11766$ vs $€ 796$, young adults $€ 15060$ vs $€ 2944$, middle aged $€ 16104$ vs $€ 4612$ and elderly $€ 18255$ vs $€ 9236$ ). The patients' annual healthcare costs were substantially higher than controls for most types of healthcare across all age groups (online supplementary tables S3-S6). However, middleaged and elderly patients had substantially lower costs of nursing homes than controls in postintervention year 1 (€866 vs $€ 2761$ ). The costs of nursing homes remained substantially lower in elderly patients in postintervention 


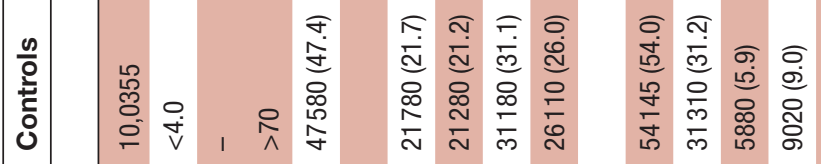

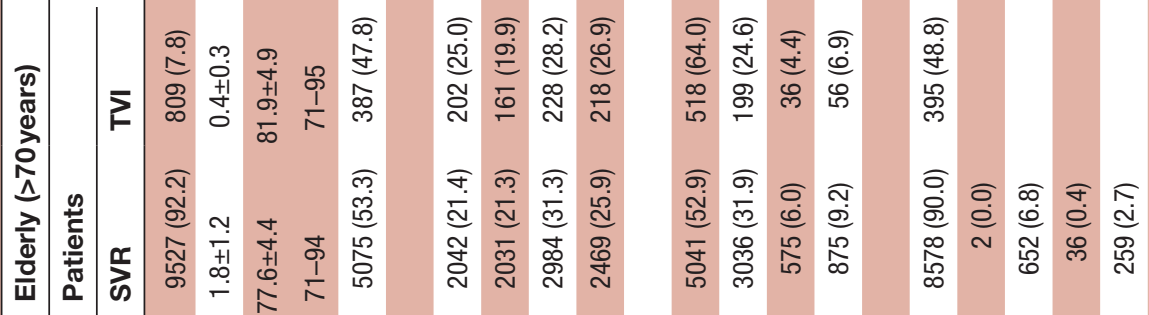

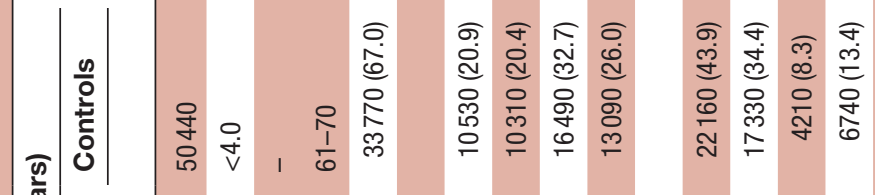

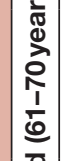

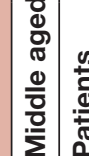

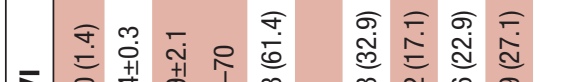

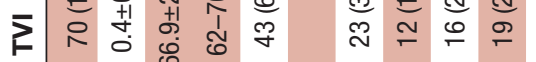

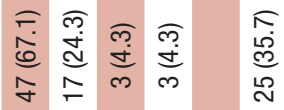

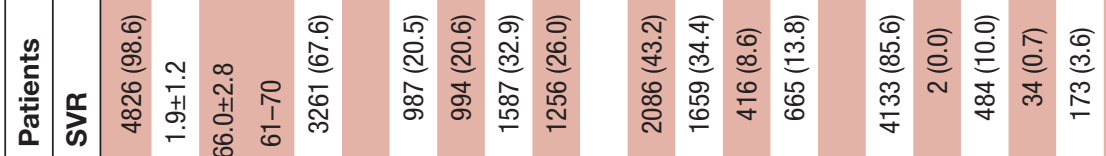

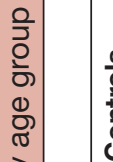

วิ

$\frac{\overline{0}}{2}$

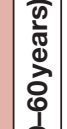

은

ठํ.

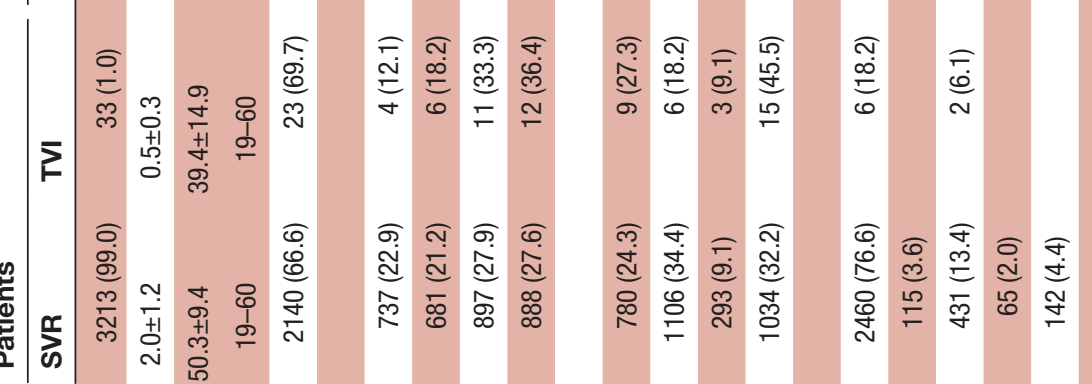

ब ๘ ल ब

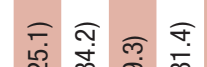

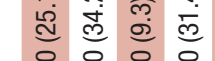

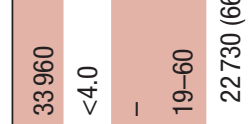

స్ 도

员通怘

눈 응 옹 \&

范

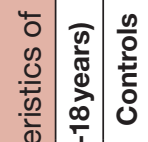

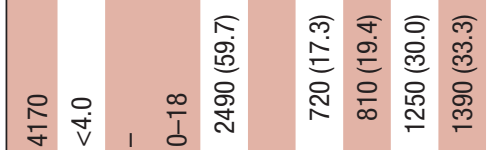

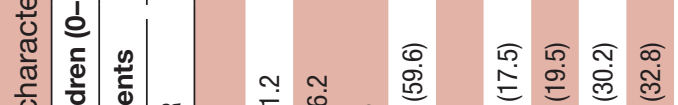

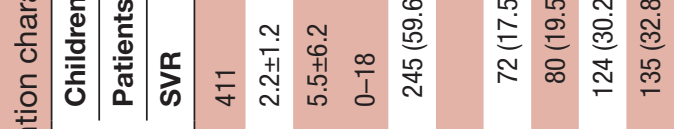

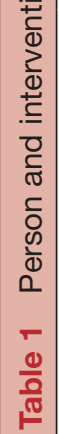

$\frac{\sqrt{2}}{\frac{8}{0}}$
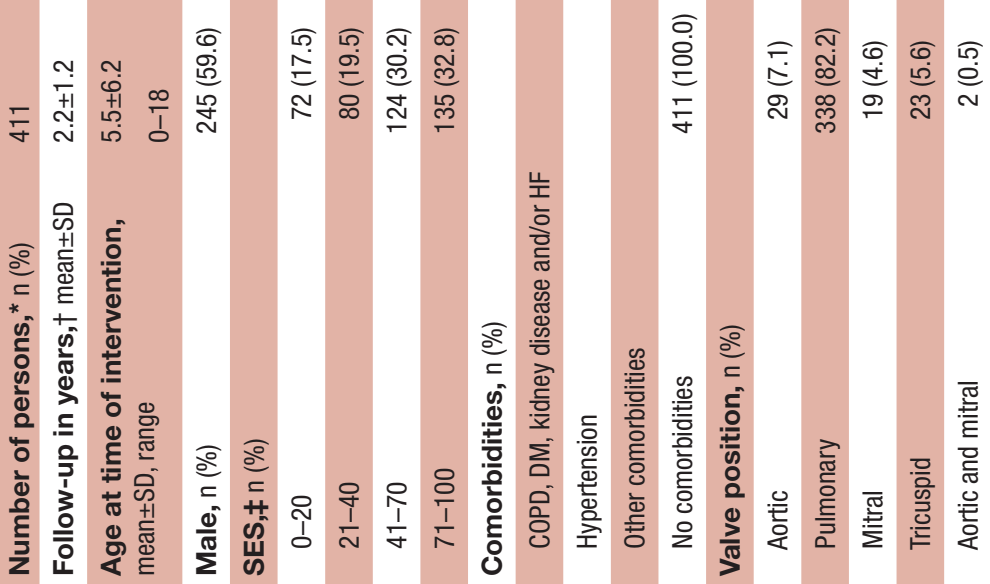

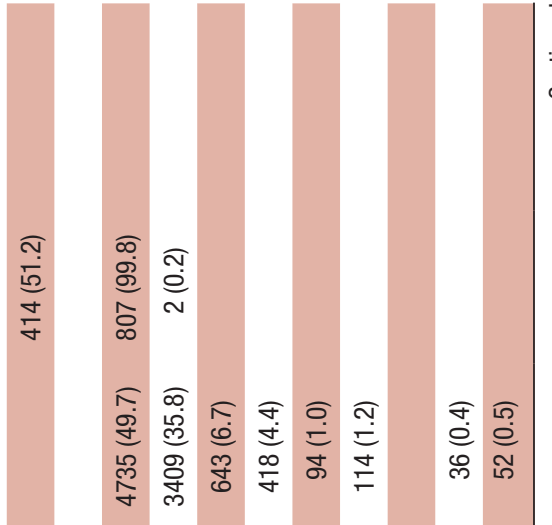

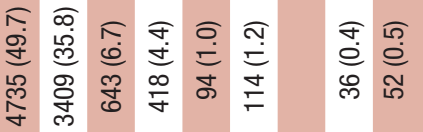

o.

$\frac{5}{5}$

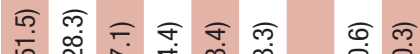

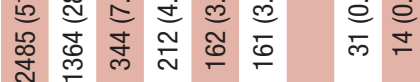

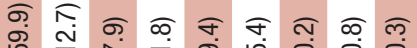

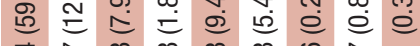

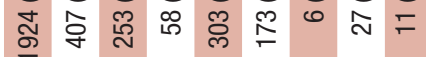

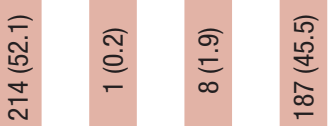

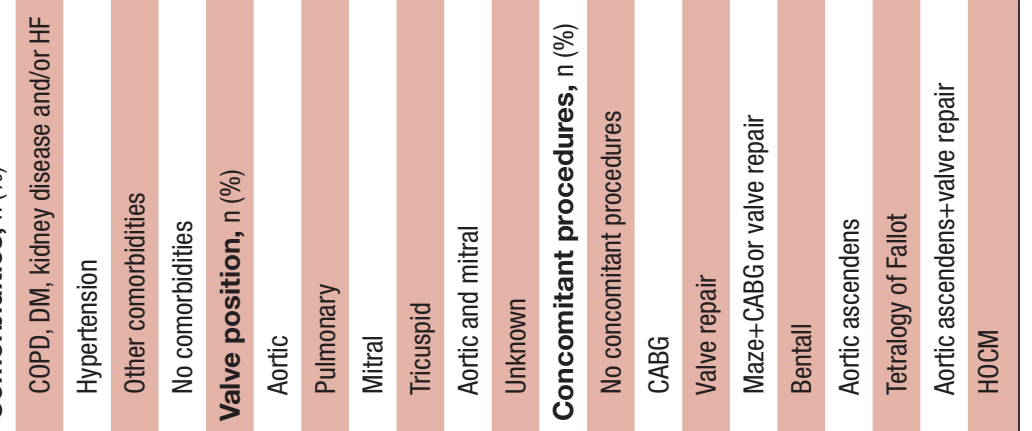


years 2 and 3 (€1763 (year 2) and €1990 (year 3) vs €2761 for controls). In addition, costs of home care were lower for elderly patients than controls in the first year after the intervention $(€ 1199$ vs $€ 1330)$.

\section{Healthcare costs: association analyses}

Table 4 presents the results of the MGLMs of annual healthcare costs for children and adult SVR patients. Annual healthcare costs for adult SVR patients increased with older age at intervention (on average $+€ 2441$ for elderly vs middle aged patients), comorbidities (on average $+€ 6543$ for patients with chronic obstructive pulmonary disease, diabetes mellitus, kidney disease and/or HF vs patients without comorbidities) and lower SES (on average $+€ 1160$ for patients with lowest vs highest SES). Men had somewhat lower costs than women (€1110 on average). If patients experience a complication, their annual healthcare costs increase on average with $€ 623$ after $\mathrm{AF}$ to $€ 30094$ after reintervention. If patients die, their costs in the year of death increase on average with $€ 6106$. For children, costs were not associated with gender or SES. The results of the GLMs for intervention and complication costs are reported in online supplementary tables S7 and S8.

\section{DISCUSSION}

Using the comprehensive Vektis databases, we were able to estimate the real-world age group-specific incidence of heart valve implantations, subsequent survival and complications as well as the associated healthcare costs of all patients in the Netherlands who had undergone a heart valve implantation during our study period. Although the estimates are specific to the Dutch healthcare system, the results regarding differences between age groups, distribution of costs over types of healthcare and associations between patient and intervention characteristics and healthcare costs are also relevant for other countries. Our results can help raise awareness of the costs associated with heart valve implantations among clinicians and healthcare policy makers, which is important in the current era of limited healthcare budgets. However, we want to emphasise that considerations about costs should not play a role in the treatment decision for individual patients. Instead the results can be used as a benchmark in cost-effectiveness analyses for new technologies that will be introduced in clinical practice in the future, such as tissue-engineered heart valves. ${ }^{5}$

This study has shown that Dutch health insurers spent over $€ 120$ million per year on procedure costs for heart valve implantations, of which $2 \%$ is spent on children, $17 \%$ on young adults, $26 \%$ on middle aged and $56 \%$ on elderly patients. Although there were no substantial differences in procedure costs between age groups, the costs of SVR were generally higher in older patients, while costs of TVI were lower for older patients. There was no trend in complication costs in relation to age groups. In addition to procedure costs, patients had excess healthcare costs 
after the heart valve implantation compared with controls in almost all types of healthcare. These excess healthcare costs were especially high in the year of heart valve implantation; 41 (children), 14 (young adults), 9 (middle aged) and 5 (elderly) fold higher in patients than controls. In the subsequent postintervention years, however, the excess healthcare costs decreased. This decrease may be explained by survival of the fittest patients.

In contrast to other types of healthcare, the costs of nursing homes were substantially lower for elderly patients than for controls. This may be caused by selection bias of relatively healthy elderly patients for SVR. Patients living in nursing homes may be less likely to undergo heart valve implantation due to other factors influencing someone's health state, such as frailty or dementia. Since these factors could not be taken into account when defining the control sample, people living in nursing homes may be over-represented in the control group as compared with the patient group.

As expected, older age, female gender, comorbidities, low SES and/or experiencing complications (including death) were associated with higher annual healthcare costs. It should be noted that the aim of this study was to describe and predict costs and that it does not make casual claims. Nevertheless, some explanations for the associations can be considered. The association of lower SES and poor health has also been shown consistently in previous research. ${ }^{10}$ The association of gender and

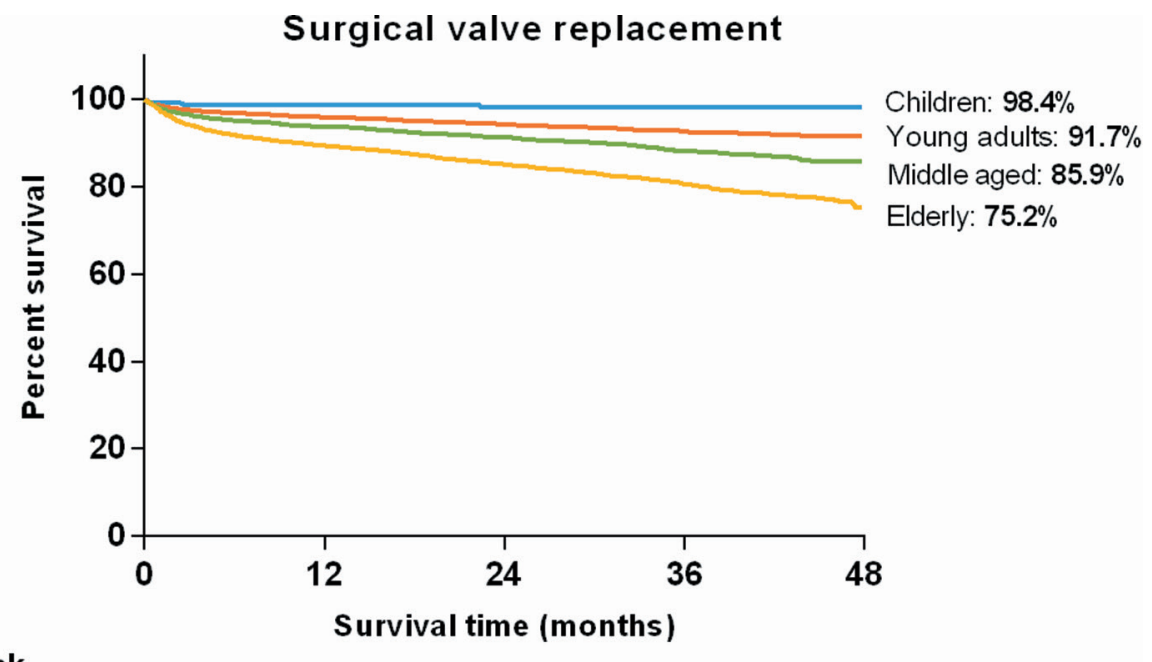

\begin{tabular}{lccccc} 
No. at risk & \multicolumn{5}{c}{} \\
Children & 411 & 321 & 236 & 135 & 0 \\
Young adults & 3,213 & 2,430 & 1,634 & 771 & 0 \\
Middle aged & 4,826 & 3,496 & 2,260 & 1,083 & 0 \\
Elderly & 9,527 & 6,674 & 4,284 & 2,049 & 0
\end{tabular}

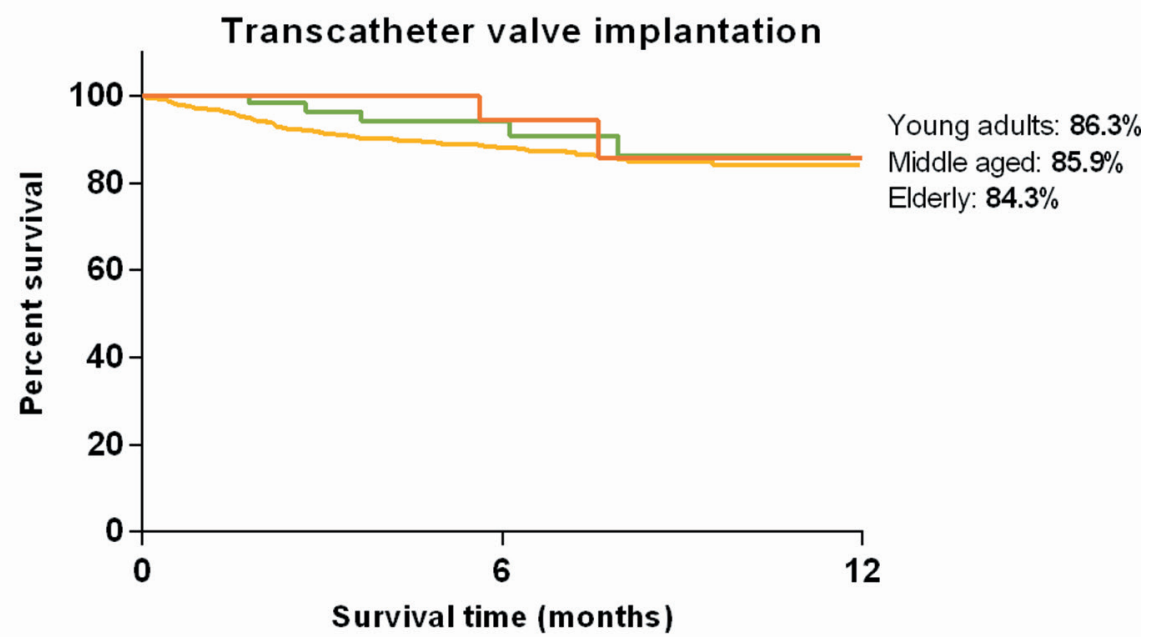

No. at risk

$\begin{array}{llll}\text { Young adults } & 33 & 18 & 0\end{array}$

Middle aged $70 \quad 29 \quad 0$

Elderly $\quad 809 \quad 332 \quad 0$

Figure 1 Kaplan-Meier curves of survival after SVR (top) and TVI (bottom) divided by age group. SVR, surgical heart valve replacement; TVI, transcatheter heart valve implantation. 


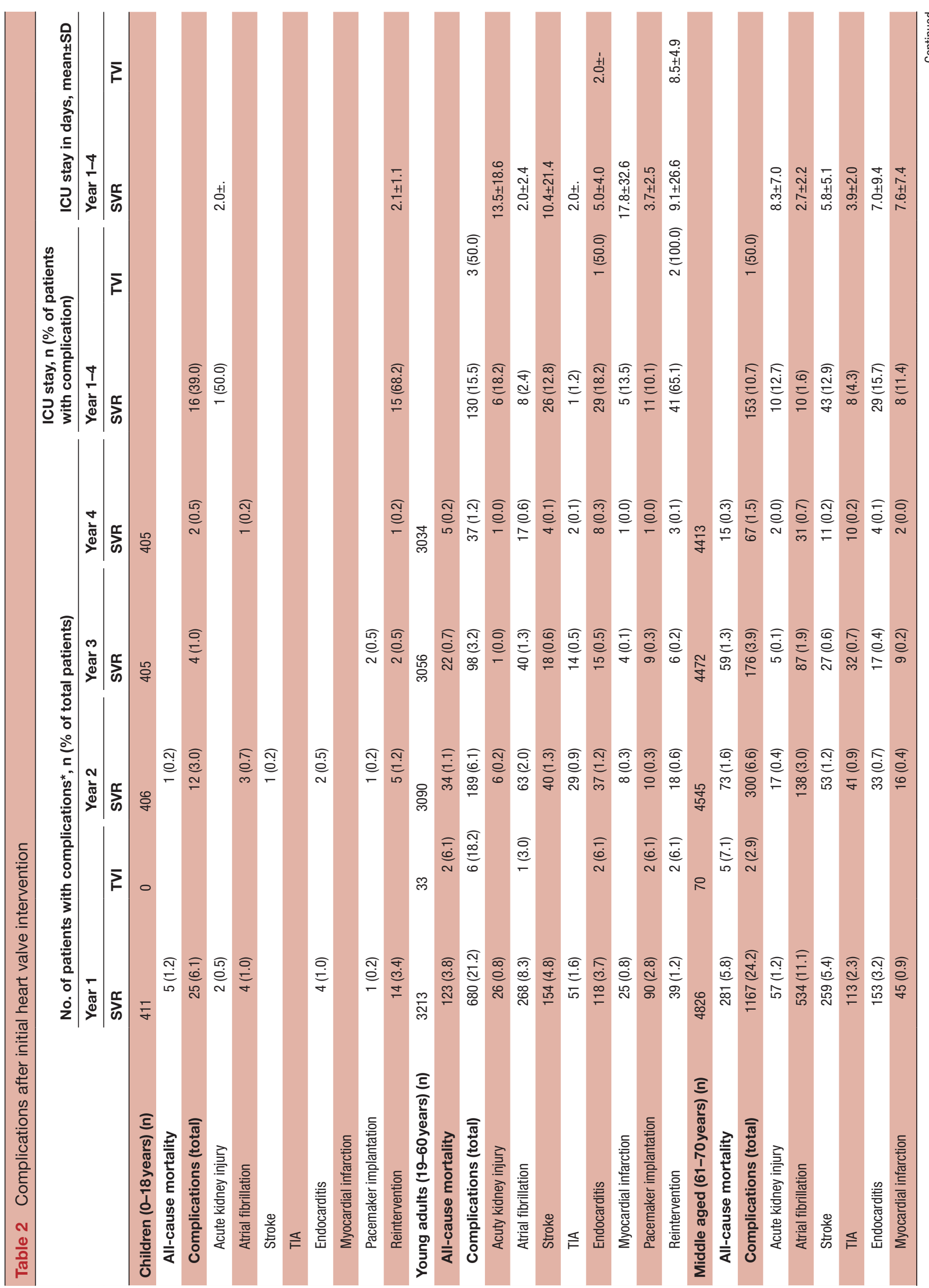

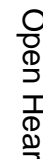

产

ธิ

के

$\overrightarrow{0}$

$\vec{\omega}$

응

$\frac{1}{3}$

กิ่

ํํㅇ 


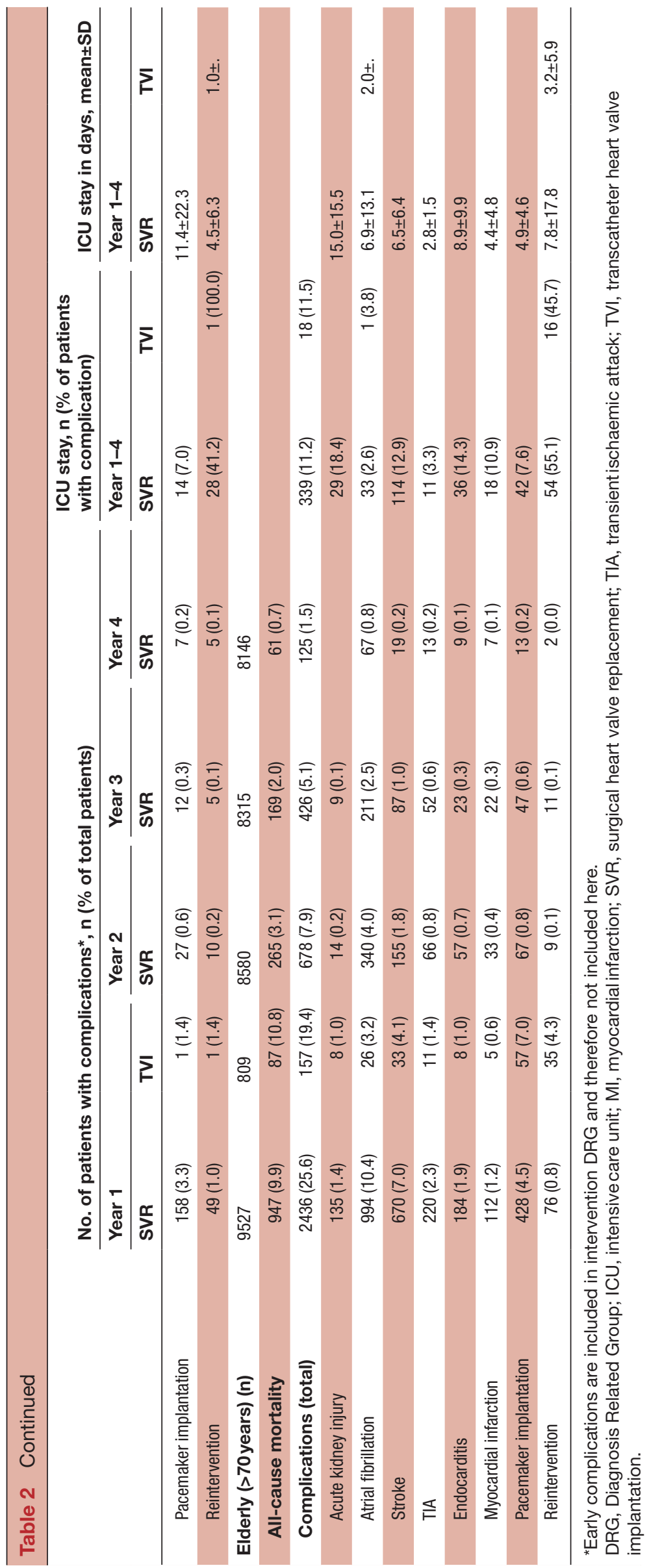


Table 3 Costs of initial heart valve intervention and complications

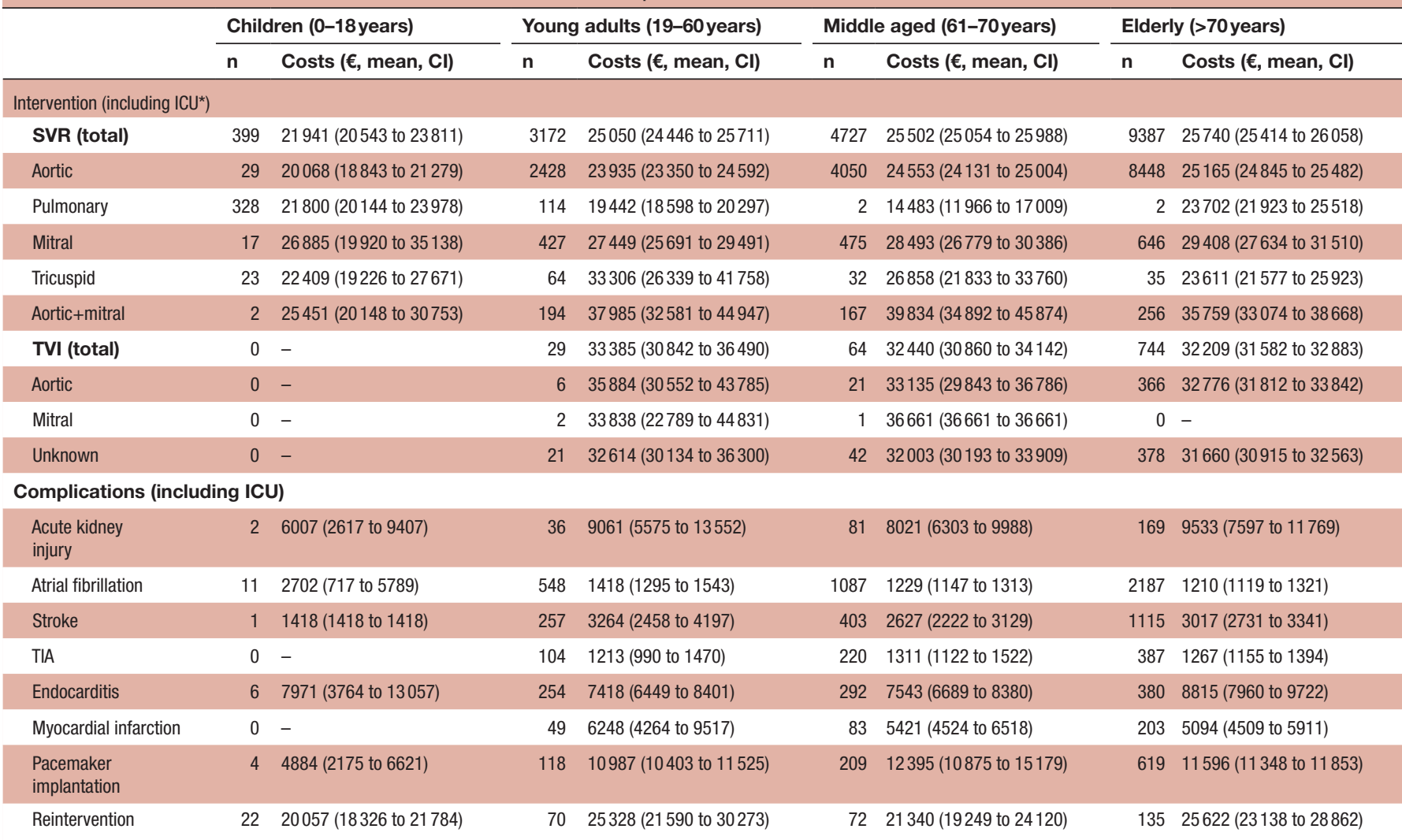

${ }^{*} \mathrm{ICU}$ costs during first year minus ICU costs after complications. Only patients with $\geq 30$-days' follow-up or died $\leq 30$ days included to ensure all ICU costs after intervention were considered.

ICU, intensive care unit; SVR, surgical heart valve replacement; TIA, transient ischaemic attack; TVI, transcatheter heart valve implantation.

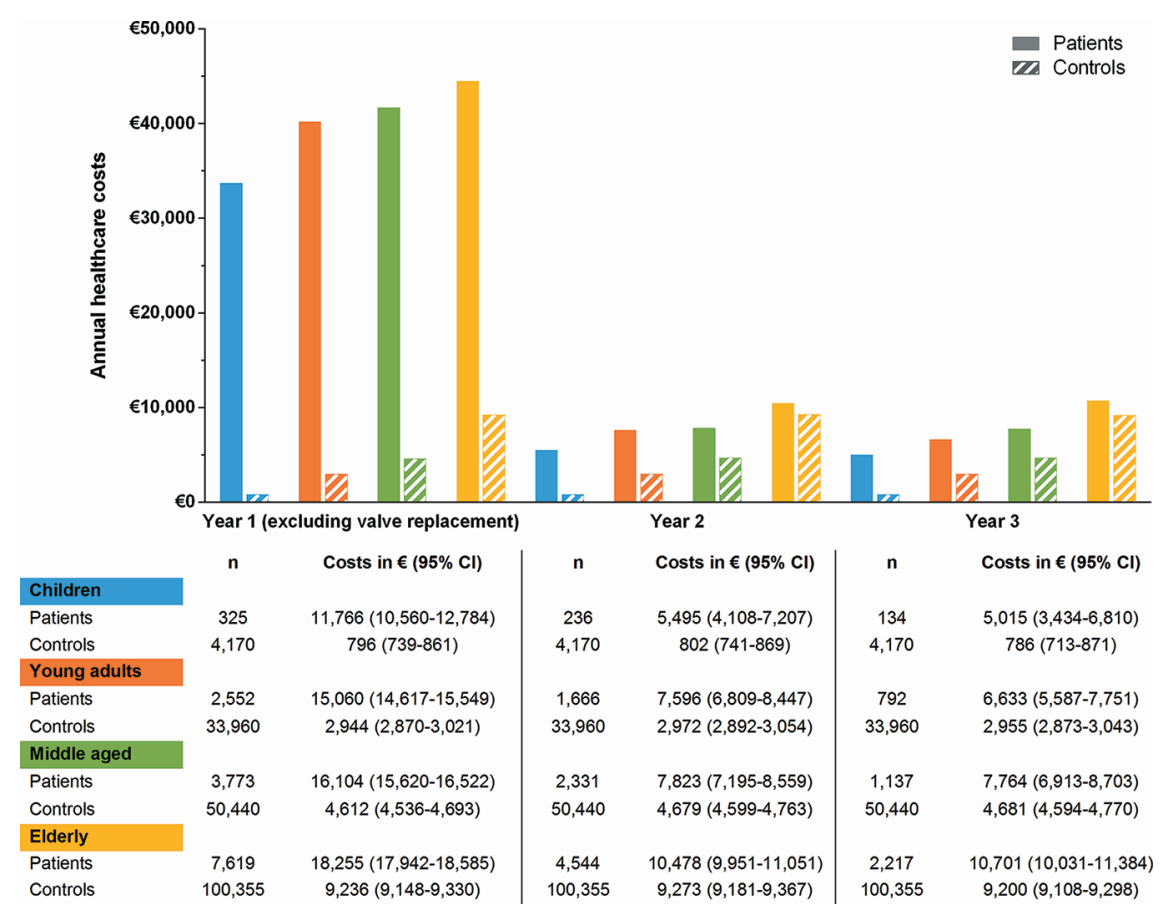

Figure 2 Annual healthcare costs during the first three postintervention years of surgical valve replacement patients and controls divided by age group.

costs, even after adjusting for comorbidities and complications, is in line with previous research that found that women have higher healthcare costs than men. ${ }^{11}$ In cardiovascular diseases, this might be due to the different preoperative risks profiles of women compared with men, ${ }^{12} 13$ which may be caused by delayed presentation or diagnosis of valve problems and/or later referral to cardiothoracic surgery of women. ${ }^{12}$ If these different risk 
Table 4 Multilevel generalised linear model of total annual healthcare costs after SVR in postintervention years 1-4

\begin{tabular}{|c|c|c|c|c|c|c|}
\hline \multirow{2}{*}{$\begin{array}{l}\text { Total costs } \\
\text { Parameter }\end{array}$} & \multicolumn{3}{|c|}{$\begin{array}{l}\text { Children } \\
(0-18 \text { years, } n=325)\end{array}$} & \multicolumn{3}{|c|}{$\begin{array}{l}\text { Adults } \\
\text { (>18years, } n=13944)\end{array}$} \\
\hline & $\beta$ & $95 \% \mathrm{Cl}$ & $P$ value & $\beta$ & $95 \% \mathrm{Cl}$ & $P$ value \\
\hline Intercept & 16931 & -36190 to 70051 & 0.533 & 11338 & 9906 to 12770 & $<0.0001$ \\
\hline \multicolumn{7}{|l|}{$\begin{array}{l}\text { Time (compared with year } 1 \text { excluding } \\
\text { intervention costs) }\end{array}$} \\
\hline Intervention period* & 21841 & 20857 to 22825 & $<0.0001$ & 25492 & 25248 to 25736 & $<0.0001$ \\
\hline Year 2 & -11519 & -67302 to 44264 & 0.686 & -2904 & -3779 to -2030 & $<0.0001$ \\
\hline Year 3 & -14952 & -67272 to 37368 & 0.576 & -1862 & -3421 to -302 & 0.019 \\
\hline Year 4 & -6170 & -64405 to 52065 & 0.836 & 396 & -1627 to 2420 & 0.701 \\
\hline Death & & & & 6106 & 4784 to 7428 & $<0.0001$ \\
\hline \multicolumn{7}{|l|}{ Age (compared with elderly) } \\
\hline \multicolumn{7}{|l|}{ Children (0-18years) } \\
\hline Young adults (19-60 years) & & & & -1179 & -2290 to -68 & 0.038 \\
\hline Middle aged (61-70 years) & & & & -2441 & -3359 to -1524 & $<0.0001$ \\
\hline Male & 1133 & -30369 to 32635 & 0.944 & -1110 & -1911 to -310 & 0.007 \\
\hline \multicolumn{7}{|l|}{$\begin{array}{l}\text { Comorbidity } \\
\text { (compared with no comorbidity) }\end{array}$} \\
\hline COPD, DM, kidney disease and/or HF & & & & 6543 & 5328 to 7757 & $<0.0001$ \\
\hline Hypertension & & & & 1309 & 67 to 2550 & 0.039 \\
\hline Other comorbidities & & & & 1990 & 218 to 3761 & 0.028 \\
\hline \multicolumn{7}{|l|}{$\begin{array}{l}\text { SES } † \text { (compared with highest SES: } \\
71-100)\end{array}$} \\
\hline SES 0-20 & 8553 & -36202 to 53308 & 0.708 & 1160 & 34 to 2285 & 0.044 \\
\hline SES $21-40$ & 2878 & -41065 to 46821 & 0.898 & 301 & -823 to 1426 & 0.599 \\
\hline SES $41-70$ & 2505 & -37038 to 42048 & 0.901 & 887 & -128 to 1901 & 0.087 \\
\hline \multicolumn{7}{|l|}{ Complications } \\
\hline Atrial fibrillation & & & & 2985 & 1673 to 4296 & $<0.0001$ \\
\hline Acute kidney inury & & & & 19639 & 16611 to 22667 & $<0.0001$ \\
\hline Stroke & & & & 7755 & 6181 to 9329 & $<0.0001$ \\
\hline TIA & & & & 623 & -2157 to 3403 & 0.661 \\
\hline Endocarditis & & & & 21572 & 18999 to 24144 & $<0.0001$ \\
\hline Myocardial infarction & & & & 13192 & 9291 to 17092 & $<0.0001$ \\
\hline Pacemaker implantation & & & & 15947 & 13816 to 18079 & $<0.0001$ \\
\hline Reintervention & & & & 30094 & 25455 to 34733 & $<0.0001$ \\
\hline
\end{tabular}

NB: 3622 SVR and all TVI patients were excluded because follow-up $<1$ year.

*Includes costs of heart valve implantation and ICU stay but no other costs of the first postintervention year (these are included in the reference group of this variable).

†Higher percentiles represent higher SES.

COPD, chronic Obstructive Pulmonary Disease; DM, diabetes mellitus; HF, heart failure; ICU, intensive care unit; SES, socioeconomic status;

SVR, surgical heart valve replacement; TIA, transient ischaemic attack.

profiles result in slower or impaired recovery of women compared with men, this might result in more use of healthcare and thereby higher annual healthcare costs.

\section{Strengths and limitations}

An important strength of our study is the use of databases including the health insurance claims of $99 \%$ of Dutch residents. Therefore, almost all patients that have undergone heart valve implantations during our study period were included, and we presented outcomes in a diverse study population that reflects the range and distribution of patients in clinical practice instead of focusing on specific age or risk groups. ${ }^{14}$ This resulted in comprehensive analyses of the real-world healthcare costs associated with heart valve implantations with high external validity and generalisability. Since healthcare decision makers need information about the cost-effectiveness in the 
real world, our results provide valuable input for the costs in cost-effectiveness analyses based on data generated in routine care instead of under experimental conditions. ${ }^{14}$ Furthermore, this study provided a unique insight in the differences in incidence, health outcomes and associated healthcare costs of heart valve implantations of patients with all ages, divided over four informative age groups.

Our study also has some limitations. First, we could not separate our results for different types of valve prostheses (eg, mechanical and biological prostheses). However, although the type of prosthesis has impact on survival and complication rates, we do not expect that the type of prosthesis has a large impact on healthcare costs. Furthermore, since the DRG code for TVI was only available from 2013, the follow-up was too short to estimate annual healthcare costs in postintervention years for these patients. Additionally, since complications were identified using DRG codes, we could only determine the incidence and costs of complications for which patients were treated in the hospital (including outpatient treatment). Furthermore, not all inhospital complications could be identified because for some complications the costs may be included in the DRG of the initial heart valve implantation instead of a separate DRG. In addition, the exact date of the heart valve implantation was unknown; instead, the opening date of the DRG in the financial administrative system was used as a proxy. It is possible that the heart valve implantation took place a few days/weeks before or after the opening date of the DRG. Furthermore, we could not calculate annual healthcare costs from the exact date of the intervention onwards but only from the quarter in which the intervention took place. Finally, the reported costs are expenditures reimbursed by health insurers based on agreements between healthcare providers and insurers, not actual costs.

\section{CONCLUSION}

This study provided a comprehensive overview of age group-specific incidence of heart valve implantations, subsequent survival and complications as well as the associated healthcare costs of all patients who had undergone a heart valve implantation in the Netherlands. We have shown that after heart valve implantation, patients have substantially higher healthcare costs than controls. The costs are higher in patients with comorbidities and patients who have experienced a complication. The costs estimated in this study can be used as a benchmark for future innovative heart valve implantations, such as tissue-engineered heart valves.
Contributors SAH was involved in the study design, data collection, statistical analysis and writing of the manuscript. JAvE was involved in the study design and data collection. LMAG contributed to the statistical analysis. JJMT and MPMHR-vM contributed to the study design, statistical analysis, interpretation of the data and writing of the manuscript. All authors read and approved the final manuscript.

Funding This work was supported by the Netherlands Cardio Vascular Research Initiative: The Dutch Heart Foundation, Dutch Federation of University Medical Centers, the Netherlands Organisation for Health Research and Development and the Royal Netherlands Academy of Sciences.

Competing interests None declared.

Provenance and peer review Not commissioned; externally peer reviewed.

Data sharing statement No additional data are available.

Open Access This is an Open Access article distributed in accordance with the Creative Commons Attribution Non Commercial (CC BY-NC 4.0) license, which permits others to distribute, remix, adapt, build upon this work non-commercially, and license their derivative works on different terms, provided the original work is properly cited and the use is non-commercial. See: http://creativecommons.org/ licenses/by-nc/4.0/

(c) Article author(s) (or their employer(s) unless otherwise stated in the text of the article) 2018. All rights reserved. No commercial use is permitted unless otherwise expressly granted.

\section{REFERENCES}

1. Coffey S, Cairns BJ, lung B. The modern epidemiology of heart valve disease. Heart 2016;102:75-85.

2. Nkomo VT, Gardin JM, Skelton TN, et al. Burden of valvular heart diseases: a population-based study. Lancet 2006;368:1005-11.

3. Yacoub MH, Takkenberg JJ. Will heart valve tissue engineering change the world? Nat Clin Pract Cardiovasc Med 2005;2:60-1.

4. Vahanian A, Alfieri O, Andreotti F, et al. Guidelines on the management of valvular heart disease (version 2012). Eur Heart $J$ 2012;33:2451-96.

5. Huygens SA, Rutten-van Mölken MP, Bekkers JA, et al. Conceptual model for early health technology assessment of current and novel heart valve interventions. Open Heart 2016;3:e000500.

6. Osnabrugge RL, Head SJ, Genders TS, et al. Costs of transcatheter versus surgical aortic valve replacement in intermediate-risk patients. Ann Thorac Surg 2012;94:1954-60.

7. Reynolds MR, Lei Y, Wang K, et al. Cost-effectiveness of transcatheter aortic valve replacement with a self-expanding prosthesis versus surgical aortic valve replacement. J Am Coll Cardiol 2016;67:29-38.

8. Sociaal Cultureel Planbureau (SCP). Statusscores 2009. 2009.

9. Lamers LM, van Vliet RC. The Pharmacy-based Cost Group model: validating and adjusting the classification of medications for chronic conditions to the Dutch situation. Health Policy 2004;68:113-21.

10. Mackenbach JP, Kunst AE, Cavelaars AEJM, et al. Socioeconomic inequalities in morbidity and mortality in western Europe. Lancet 1997;349:1655-9.

11. Cylus J, Hartman M, Washington B, et al. Pronounced gender and age differences are evident in personal health care spending per person. Health Aff 2011;30.

12. Ibrahim MF, Paparella D, Ivanov J, et al. Gender-related differences in morbidity and mortality during combined valve and coronary surgery. $J$ Thorac Cardiovasc Surg 2003;126:959-64.

13. Mokhles MM, Siregar S, Versteegh MI, et al. Male-female differences and survival in patients undergoing isolated mitral valve surgery: a nationwide cohort study in the Netherlands. Eur J Cardiothorac Surg 2016;50:482-7.

14. Garrison LP, Neumann PJ, Erickson P, et al. Using real-world data for coverage and payment decisions: the ISPOR Real-World Data Task Force report. Value Health 2007;10:326-35. 


\section{Correction: How much does a heart valve implantation cost and what are the health care costs afterwards?}

Huygens SA, Goossens LMA, van Erkelens JA, et al. How much does a heart valve implantation cost and what are the health care costs afterwards? Open Heart 2018;5:e00672. doi: 10.1136/openhrt-2017-000672.

There is a mistake in figure 2 and it should be replaced with the following:

Figure 2 Annual healthcare costs during the first three postintervention years of surgical valve replacement patients and controls divided by age group.

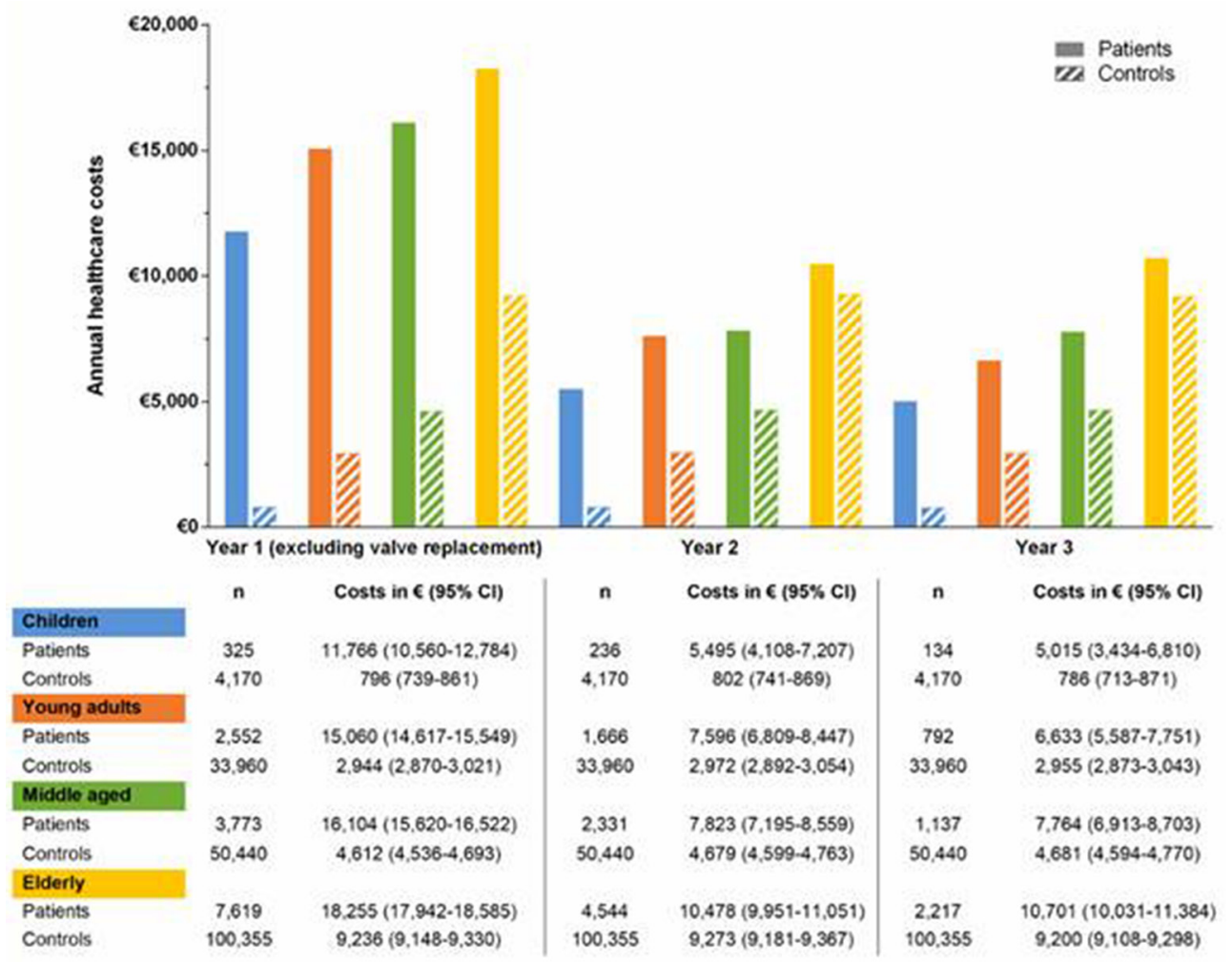

Open Access This is an Open Access article distributed in accordance with the Creative Commons Attribution Non Commercial (CC BY-NC 4.0) license, which permits others to distribute, remix, adapt, build upon this work non-commercially, and license their derivative works on different terms, provided the original work is properly cited and the use is non-commercial. See: http:// creativecommons.org/licenses/by-nc/4.0/

Open Heart 2018;5:e000672corr1. doi:10.1136/openhrt-2017-000672corr1

A) Check for updates 